\title{
Prevalence of use of advance directives, health care proxy, legal guardian, and living will in 512 patients hospitalized in a cardiac care unit/intensive care unit in 2 community hospitals
}

Anil Kumar ${ }^{1}$, Wilbert S. Aronow ${ }^{2}$, Margelusa Alexa1 ${ }^{1}$ Ritu Gothwal', Stephen Jesmajian ${ }^{1,2}$, Bharat Bhushan ${ }^{3}$, Praveen Gaba3 , James Catevenis ${ }^{3}$

${ }^{1}$ Departments of Medicine, Sound Shore Medical Center, USA

2New York Medical College, Valhalla, NY, USA

${ }^{3}$ New Rochelle, NY, Prince George's Hospital Center, Cheverly, Maryland, USA

Submitted: 9 February 2010

Accepted: 7 April 2010

Arch Med Sci 2010; 6, 2: 188-191

DOI: 10.5114/aoms.2010.13892

Copyright (c) 2010 Termedia \& Banach

\author{
Corresponding author: \\ Wilbert S. Aronow, MD \\ Cardiology Division \\ New York Medical College \\ Macy Pavilion, room 138 \\ Valhalla, NY 10595, USA \\ Phone: (914) 493-5311 \\ Fax: (914) 235-6274 \\ E-mail: wsaronow@aol.com
}

\begin{abstract}
Introduction: The prevalence of use of any advance directives was $26 \%$ in 112 patients hospitalized in a cardiac care unit (CCU)/intensive care unit (ICU) in an academic medical center.

Material and methods: We investigated in 2 community hospitals the prevalence of use of advance directives (AD), health care proxy (HCP), legal guardian (LG), and living will (LW) in 512 patients hospitalized in a CCU/ ICU approached for $\mathrm{AD}$ and HCP.

Results: The use of AD was $22 \%$, of HCP was $19 \%$, of LG was $16 \%$, and of LW was $5 \%$.

Conclusions: The use of AD was $22 \%$, of HCP was $19 \%$, of LG was $16 \%$, and of LW was $5 \%$ in patients hospitalized in a CCU/ICU. Educational programs on use of $A D$ and of HCP need to be part of cardiovascular training programs and of cardiovascular continuing medical education.
\end{abstract}

Key words: advance directives, health care proxy.

\section{Introduction}

Cardiovascular disease is the number one cause of death in the United States [1-9]. American College of Cardiology/American Heart Association guidelines recommend the discussion of advance directives with patients who have congestive heart failure [10]. The federal Patient SelfDetermination Act passed on November 5, 1990 mandates discussion of advance directives with all hospitalized adults [11]. One study found the prevalence of use of any advance directives in 112 patients hospitalized in a cardiac care unit in an academic medical center was $26 \%$ [12]. The present study reports the prevalence of use of advance directives, health care proxy, legal guardian, and living will in 512 patients hospitalized in a cardiac care unit/intensive care unit in 2 community hospitals. 


\section{Material and methods}

We performed a chart review investigating the prevalence of use of advance directives, health care proxy, legal guardian, and living will in 312 patients hospitalized in the cardiac care unit/intensive care unit at Sound Shore Medical Center in New Rochelle, New York and in 200 patients hospitalized in the cardiac care unit/intensive care unit at Prince George's Hospital Center in Cheverly, Maryland who were approached for the use of advance directives and health care proxy. The 512 patients included 290 men and 222 women, mean age $61 \pm 19$ years. Of the 512 patients, 242 (47\%) were whites, and 270 (53\%) were nonwhites. Of the 512 patients, 279 (55\%) were younger than 65 years, 141 (28\%) were aged 65-79 years, and 92 (18\%) were aged $\geq 80$ years. This study has been approved by our Institutional Review Boards.

\section{Results}

Table I shows the prevalence of use of advance directives, health care proxy, legal guardian, and living will in the 512 patients hospitalized in a cardiac care unit/intensive care unit. Table II shows the prevalence of use of advance directives, health care proxy, legal guardian, and living will in
290 men and 222 women hospitalized in a cardiac care unit/intensive care unit. No significant differences were found.

Table III shows the prevalence of use of advance directives, health care proxy, legal guardian, and living will in 242 whites and 270 nonwhites hospitalized in a cardiac care unit/intensive care unit. Table III also lists levels of statistical significance. Table IV shows the prevalence of use of advance directives, health care proxy, legal guardian, and living will in 279 patients younger than 65 years, in 141 patients aged 65-79 years, and in 92 patients aged $\geq 80$ years hospitalized in a cardiac care unit/intensive care unit. Table IV also lists levels of statistical significance.

Table I. Prevalence of use of advance directives, health care proxy, legal guardian, and living will in 512 patients hospitalized in a cardiac care unit/intensive care unit

\begin{tabular}{|lc|}
\hline Variable & Number (\%) \\
\hline Advance directives & $114(22 \%)$ \\
\hline Health care proxy & $97(19 \%)$ \\
\hline Legal guardian & $80(16 \%)$ \\
\hline Living will & $23(5 \%)$ \\
\hline
\end{tabular}

Table II. Prevalence of use of advance directives, health care proxy, legal guardian, and living will in men versus women hospitalized in a cardiac care unit/intensive care unit

\begin{tabular}{|lccl|}
\hline Variable & $\begin{array}{c}\text { Men } \\
(n=290)\end{array}$ & $\begin{array}{c}\text { Women } \\
(n=222)\end{array}$ & Value of $p$ \\
\hline Advance directives & $60(21 \%)$ & $54(24 \%)$ & Not significant \\
\hline Health care proxy & $53(18 \%)$ & $44(20 \%)$ & Not significant \\
\hline Legal guardian & $48(17 \%)$ & $32(14 \%)$ & Not significant \\
\hline Living will & $12(4 \%)$ & $11(5 \%)$ & Not significant \\
\hline
\end{tabular}

Table III. Prevalence of use of advance directives, health care proxy, legal guardian, and living will in whites versus nonwhites hospitalized in a cardiac care unit/intensive care unit

\begin{tabular}{|lccc|}
\hline Variable & $\begin{array}{c}\text { Whites } \\
(n=242)\end{array}$ & $\begin{array}{c}\text { Nonwhites } \\
(n=270)\end{array}$ & Value of $p$ \\
\hline Advance directives & $70(29 \%)$ & $44(16 \%)$ & $<0.001$ \\
\hline Health care proxy & $36(15 \%)$ & $61(23 \%)$ & $<0.05$ \\
\hline Legal guardian & $29(12 \%)$ & $51(19 \%)$ & $<0.05$ \\
\hline Living will & $19(8 \%)$ & $4(2 \%)$ & $<0.001$ \\
\hline
\end{tabular}

Table IV. Prevalence of use of advance directives, health care proxy, legal guardian, and living will in patients aged $<65$ years, 65-79 years, and $\geq 80$ years hospitalized in a cardiac care unit/intensive care unit

\begin{tabular}{|lccc|}
\hline Variable & $\begin{array}{c}<6 \text { Years } \\
(n=279)\end{array}$ & $\begin{array}{c}65-79 \text { Years } \\
(n=141)\end{array}$ & $\begin{array}{c}\geq 80 \text { Years } \\
(n=92)\end{array}$ \\
\hline Advance directives & $50(18 \%)$ & $35(25 \%)$ & $29(32 \%)$ \\
\hline Health care proxy & $53(19 \%)$ & $28(20 \%)$ & $16(17 \%)$ \\
\hline Legal guardian & $42(15 \%)$ & $20(14 \%)$ & $18(20 \%)$ \\
\hline Living will & $6(2 \%)$ & $12(9 \%)$ & $5(5 \%)$ \\
\hline
\end{tabular}

For advance directives, $p<0.01$ comparing $\geq 80$ years with $<65$ years. For living will, $p<0.005$ comparing $65-79$ years with $<65$ years 


\section{Discussion}

Cardiovascular disease is the number one cause of death in the United States [1-9]. Advance directives would seem to be an important part of cardiovascular disease management. Heart failure has a worse prognosis than many cancers [13]. Half of heart failure patients die from sudden cardiac death and half from pump failure [14]. Advance directives may be more important for care of heart failure patients than for cancer patients in whom a terminal phase is identified [14]. Advance directives should be a part of management of patients with heart failure [10, 15] and other cardiovascular disorders. Barriers to creating and documenting advance directives include reluctance of physicians and discomfort of physicians in discussing advance directives with patients and their families [16].

Of 112 patients, mean age 58 years, hospitalized in a cardiac care unit in an academic medical; center, 29 patients (26\%) had any advance directives [12]. Seven of the 112 patients (6\%) had a living will as their advance directives. This low prevalence of use of advance directives occurred despite the federal Patient Self-Determination Act of 1990 mandating that all hospitalized adults be given the opportunity to have advance directives [11].

The present study of 512 patients hospitalized in a cardiac care unit/intensive care unit in 2 community hospitals showed that the prevalence of use of advance directives was $22 \%$, of a health care proxy was $19 \%$, of a legal guardian was $16 \%$, and of a living will was $5 \%$. The prevalence of use of advance directives, of a health care proxy, of a legal guardian, and of a living will was not significantly different between hospitalized men and women. Whites were significantly more likely to have advance directives and a living will than nonwhites. Nonwhites were significantly more likely to have a health care proxy and a legal guardian than whites. Patients aged $\geq 80$ years were significantly more likely to have advance directives than patients younger than 65 years. Patients aged 65-79 years were significantly more likely to have a living will than patients younger than 65 years.

The results from the present study and a smaller previously published study [12] showed a low prevalence of use of advance directives. To the best of our knowledge, there are no other published studies showing the prevalence of use of advance directives in a cardiac care unit/intensive care unit. Cardiovascular training programs and cardiovascular continuing medical education programs need to include discussions on advance directives, especially with the population of elderly cardiovascular disease patients growing. Physicians should be educated to try to obtain advance directives in all patients hospitalized in a cardiac care unit/intensive care unit. A copy of advance directives if available should be sent with the patient whenever transferred to a hospital or emergency department. An association between advance directives and quality of end-oflife care has been reported [17].

None of the authors have any conflicts of interest.

\section{References}

1. Lai HM, Aronow WS, Rachdev A, et al. Incidence of mortality in 1,040 patients with coronary heart disease or hypertensive heart disease with normal and abnormal left ventricular ejection fraction and with normal and abnormal QRS duration. Arch Med Sci 2008; 4: 140-2.

2. Lleva $\mathrm{P}$, Aronow WS, Amin $\mathrm{H}$, et al. Prevalence of electrocardiographic abnormalities in patients with ischemic stroke, intracerebral hemorrhage, and subarachnoid hemorrhage. Arch Med Sci 2008; 4: 259-62.

3. Cronin A, Aronow WS, Devabhakturi S, et al. Prevalence of incidental noncardiac findings diagnosed by computer tomography in 875 consecutive patients in an outpatient cardiac computer tomography facility. Arch Med Sci 2008; 4: 401-3.

4. Ramdeen N, Aronow WS, Chugh S, et al. Patients undergoing coronary angiography because of chest pain with hepatitis $C$ seropositivity have a higher prevalence of obstructive coronary artery disease than a control group. Arch Med Sci 2008; 4: 452-4.

5. Rachdev A, Aronow WS, Lai H, et al. Comparison of left ventricular ejection fraction by single photon computed tomographic myocardial perfusion imaging versus coronary computed tomography angiography. Arch Med Sci 2009; 5: 28-31.

6. Kannam H, Aronow WS, Chilappa K, et al. Association of the QRS duration on the resting electrocardiogram with the severity of coronary artery disease in 2,196 patients undergoing coronary angiography for suspected coronary artery disease. Arch Med Sci 2009; 5: 163-5.

7. Shao JH, Aronow WS, Ravipati G, et al. Prevalence of a minimal luminal cross sectional area of coronary arteries <4 mm2 determined by intravascular ultrasound in patients with coronary artery calcium scores of 0-100, 100200, 200-300, 300-400, and $>400$ determined by cardiac computer tomography. Arch Med Sci 2009; 5: 172-4.

8. Ravipati G, Aronow WS, Kumbar S, et al. Patients with diabetes mellitus with ischemic stroke have a higher hemoglobin A1c level and a higher serum low-density lipoprotein cholesterol than diabetics without ischemic stroke. Arch Med Sci 2009; 5: 391-3.

9. Amin $\mathrm{H}$, Aronow WS, Lleva $\mathrm{P}$, et al. Prevalence of transthoracic echocardiographic abnormalities in patients with ischemic stroke, intracerebral hemorrhage, and subarachnoid hemorrhage. Arch Med Sci 2010; 6: 40-2.

10. Hunt SA, Abraham WT, Feldman AM, et al. ACC/AHA 2005 guideline update for the diagnosis and management of chronic heart failure in the adult-summary article. A report of the American College of Cardiology/American Heart Association Task Force on Practice Guidelines (Writing Committee to Update the 2001 Guidelines for the Evaluation and Management of Heart Failure). Developed in collaboration with the American College of Chest Physicians and the International Society for Heart and Lung Transplantation. Endorsed by the Heart Rhythm Society. J Am Coll Cardiol 2005; 46: 1116-43. 
11. Patient Self-Determination Act in Omnibus Budget Reconciliation Act of 1990. Federal Law 1990; 101-508.

12. Kirkpatrick JN, Guger CJ, Arnsdorf MF, Fedson SE. Advance directives in the cardiac care unit. Am Heart J 2007; 154: 477-81.

13. The SUPPORT Principal Investigators. A controlled trial to improve care for seriously ill hospitalized patients. The study to understand prognosis and preferences for outcomes and risks of treatments (SUPPORT). JAMA 1995; 274: 1591-8.

14. Lane RE, Cowie MR, Chow AW. Prediction and prevention of sudden cardiac death in heart failure. Heart 2005; 91: 674-80.

15. Goodlin SJ. Palliative care in congestive heart failure. J Am Coll Cardiol 2009; 54: 386-96.

16. Gupta G, Aronow WS. Prevalence of the use of advance directives among residents of an academic long-term care facility. Geriatr Aging 2008; 11: 41-2.

17. Teno JM, Gruneir A, Schwartz Z, et al. Association between advance directives and quality of end-of-life care: a national study. J Am Geriatr Soc 2007; 55: 189-94. 